\title{
VISION HUMANA Y CRISTIANA DEL DESARROLLO SOCIAL: BENEDICTO XVI
}

\author{
José Luis Santos ${ }^{1}$ \\ Universidad Complutense / Universidad San Pablo CEU
}

\begin{abstract}
Resumen:
Un análisis sobre el desarrollo en una sociedad globalizada, según la visión cristiana desde el Evangelio, es expresado en su tercera encíclica "Caritas in veritate", caridad en la verdad, (2009), por el Papa Benedicto XVI, Joseph Ratzinger, de reconocido sólido perfil teológico y magisterial. Caridad en la verdad en el cristianismo es principio operativo que trata de profundizar no en sentimientos marginales de la sociedad, sino en criterios orientadores, dos de ellos de máxima repercusión: la justicia y el bien común. Benedicto XVI considera el desarrollo humano en la reflexión actual, enumera previamente algunas desviaciones de gran alcance, bien conocidas en la esfera internacional, y extiende su mirada a continuación, desde la conciencia cristiana y desde la dimensión trascendente del hombre, sobre el hombre, sobre sus derechos y obligaciones en el progreso humano y sobre la familia humana global, centro y finalidad del desarrollo de los pueblos.
\end{abstract}

Palabras clave: Benedicto XVI, Encíclica, Caritas in Veritate, justicia, bien común, progreso humano.

Title in English: "A Christian and Human Vision on Social Development: Benedict XVI"

\begin{abstract}
:
Pope Benedict XVI, in his third encyclical "Caritas in Veritate," Charity in Truth, (2009) makes an analysis from the Christian perspective, on the development in a globalized society. Charity in truth in Christianity is the operating principle that attempts to explore in depth the principal guiding criteria for human beings, two of them of maximum impact: justice and the common good. Benedict XVI makes some considerations on human development in the current debate. He mentions some important deviations, well known in the international arena, and then from the perspective of the Christian conscience and its transcendental dimension looks into the human beings, their rights and obligations on human progress and into the global human family, as the center and purpose of the development of peoples.
\end{abstract}

Keywords: Benedict XVI, Encyclical, Caritas in Veritate, Justice, Common Good, Human Progress.

Copyright $\odot$ UNISCI, 2013.

Las opiniones expresadas en estos artículos son propias de sus autores, y no reflejan necesariamente la opinión de UNISCI. The views expressed in these articles are those of the authors, and do not necessarily reflect the views of UNISCI.

\footnotetext{
${ }^{1}$ José Luis Santos Díez es Catedrático Emérito de Derecho Canónico y Derecho Eclesiástico del Estado de la Universidad Complutense de Madrid y la Universidad San Pablo-CEU. Sus principales líneas de investigación son el Derecho Canónico, las relaciones Iglesia-Estado y los acuerdos entre la Santa Sede y los Estados. E-mail: jlsdiez@yahoo.es.
} 


\section{Introducción}

En artículo editorial de Benedicto XVI, en diario londinense "Financial Times",Navidad de 2012, un par de meses anterior a su renuncia al Pontificado, (original petición de la dirección del periódico financiero al supremo director espiritual de los católicos) aparece, entre otras sugerencias, la que podría considerarse como ruta de las siguientes líneas de comentario a su encíclica "Caritas in veritate": "Los cristianos no deberían escapar del mundo; por el contrario deberían implicarse en el; pero su participación en la política y en la economía debería trascender toda forma de ideología...La fe cristiana en el destino trascendente de cada ser humano implica la urgencia de la tarea de promover la paz y la justicia para todos. Debido a que tales fines son compartidos por muchos, es posible una gran y fructífera colaboración entre los cristianos y los demás." 2

Al dirigir la mirada, en efecto, a la dimensión humana y cristiana del desarrollo social en las encíclicas de Benedicto XVI (en adelante, B XVI), la atención se centra en la tercera de sus tres encíclicas: "Caritas in veritate", caridad en la verdad, (2009), ${ }^{3}$ una especie de continuación de la "Populorum progressio" de Pablo VI (1967), y un análisis de lo que la visión cristiana desde el Evangelio sugiere a B XVI el desarrollo en una sociedad globalizada.

Las otras dos encíclicas de B XVI, "Deus est amor", Dios es amor, 2005, y"Spe salvi", Salvados en la esperanza, 2007, aunque no carecen de referencias al desarrollo social humano, se dirigen también a los fieles de la Iglesia desde una reflexión más extrictamente religiosa. La primera "Deus est amor", , sobre el amor de Dios Padre hacia los hombres, sobre Cristo como expresión del amor de Dios en su vida histórica entre los hombres y sobre el amor del hombre a Dios y al prójimo. Como se ha comentado, representa como una respuesta a la posibilidad de amar a Dios y al prójimo y como un deber de la Iglesia de practicar y enseñar el servicio de la caridad, partiendo desde luego desde la justicia.

La segunda encíclica "Spe salvi",5 realiza una reflexión sobre la esperanza cristiana en los fieles de la Iglesia, como expresión de fé, profundizando en su naturaleza, fisonomía y consecuencias para el tiempo presente y su significado trascendente más allá de la frontera de esta vida. Constituye una esperanza fiable para el creyente al conocer que su vida tiene un futuro, que no acaba en el vacío, y que se actúa mediante una práctica viva. La esperanza del futuro influye en la realidad del presente.

\section{Propuesta libre desde el Evangelio}

Interesa destacar previamente la reflexión de B XVI, en su tercera encíclica "Caritas in veritate", dirigida fundamentalmente a los fieles de la Iglesia, como propuesta libre desde el Evangelio, desde donde parte su enfoque en la compleja circunstancia actual del hombre y de los pueblos ya que su misión se refiere al orden espiritual y religioso del hombre, de libre aceptación por cualquier persona: "La Iglesia no tiene soluciones técnicas que ofrecer (señala B XVI, siguiendo a "Gaudium et spes"del Vaticano II, y"Populorum progressio" de Pablo

\footnotetext{
${ }^{2}$ Benedicto XVI: "editorial”, Financial Times, 21 Diciembre 2012.

${ }^{3}$ Benedicto XVI: "Caritas in veritate", carta encíclica, AAS 101 (2009) 641-709 (7 julio 2009).

${ }^{4}$ Benedicto XVI: "Deus est amor", carta encíclica, AAS 98 (2006) 217-252 (25 diciembre 2005).

${ }^{5}$ Benedicto XVI: “Spe salvi”, carta encíclica, AAS 99 (2007) 985-1027 (30 noviembre 2007).
} 
$V I)^{6}$ y no pretende «de ninguna manera mezclarse en la política de los Estados». "No obstante, tiene una misión de verdad que cumplir en todo tiempo y circunstancia en favor de una sociedad a medida del hombre, de su dignidad y de su vocación... El compartir los bienes y recursos, de lo que proviene el auténtico desarrollo, no se asegura sólo con el progreso técnico y con meras relaciones de conveniencia, sino con la fuerza del amor que vence al mal con el bien ( $c f$. Rm 12,21) y abre la conciencia del ser humano a relaciones recíprocas de libertad y de responsabilidad" (n. 9) .

Tratando de humanización en países africanos en reciente encuentro de "Antropología y misión", Mons. Paride Tabán, candidato propuesto al Premio Nobel de la Paz (2013), obispo emérito de Tobit en Sudán del Sur, después de larga experiencia, comunicaba un excelente mensaje en la línea de la encíclica de B XVI: "El arma más potente que tenemos en este mundo no es un fusil o una bomba, sino el amor, que es el alma de la paz,"7.

La Iglesia, al realizar el análisis del desarrollo en su dimensión humana y cristiana, lo hace como puede hacerlo cualquier otra persona o institución capacitada para apreciar la ruta humana en orden al bien del hombre y al bien de la comunidad social. Su doctrina, como toda la doctrina social de la Iglesia, sin fuerza jurídica ante los pueblos y sus dirigentes, es una propuesta libre desde el Evangelio, susceptible de interés para quien quiera estudiarla.

Por otra parte la reflexión de la encíclica y toda la actividad de sus ocho años de Pontificado viene garantizada por un pensador de prestigio a escala universal en la Iglesia y en la sociedad con anterioridad a su llegada al Pontificado, con sólido perfil teológico y magisterial de escritor, profesor y pensador, como es Benedicto XVI, Joseph Ratzinger. Su capacidad intelectual en el análisis de las doctrinas, su preparación en Teología y disciplinas complementarias, su dilatado profesorado en la universidades públicas de su país, Bonn, Münster, Tubinga y Regensburg, además de otros cargos eclesiásticos de responsabilidad, y su infinidad de publicaciones, libros y artículos de la especialidad, han logrado un magisterio luminoso y de solvencia reconocida.

\section{Intencionalidad de la Encíclica "Caritas in Veritate"}

Las líneas siguientes, con intención simplicadora de la encíclica y con frecuente apelación al texto de viva y luminosa precisión, pretenden subrayar el pensamiento de B XVI en dos o tres aspectos de su análisis sobre el desarollo social de la humanidad, especialmente en lo que se refiere al desarrollo en la reflexión actual, en los derechos y deberes humanos sobre el desarrollo y la consideración de la humanidad como familia humana global.

La primera sugerencia de la encíclica nace de su propio título "Caritas in veritate", "Caridad en la verdad", escogida sin duda intencionalmente como elemento sustantivo en que gira la doctrina social de la Iglesia: "La caridad es la vía maestra de la doctrina social de la Iglesia. Todas las responsabilidades y compromisos trazados por esta doctrina provienen de la caridad que, según la enseñanza de Jesús, es la síntesis de toda la Ley (cf. Mt 22,36-40). Ella da verdadera sustancia a la relación personal con Dios y con el prójimo; no es sólo el

\footnotetext{
${ }^{6}$ Concilio Ecuménico Vaticano II sobre la Iglesia en el mundo actual: "Gaudium et spes", constitución pastoral, no. 26., AAS 58 (1966) (7 diciembre1965), pp. 1025-1115; Pablo VI: "Populorum progressio", carta encícilica, 22: AAS 59 (1967) (26 marzo 1967), pp. 257-299.

7 A.J. Eisman (2013): Paride Taban, constructor de paz en Sudán, Madrid, Mundo Negro; XXV Encuentro, “Antropología y misión”, Edit. Mundo Negro, Madrid (2-3 febrero 2013).
} 
principio de las micro-relaciones, como en las amistades, la familia, el pequeño grupo, sino también de las macro-relaciones, como las relaciones sociales, económicas y políticas". (n. 2)

La desviación y pérdida de sentido de la palabra "caridad" en la sociedad actual y en la misma sociedad cristiana, con el consiguiente rechazo, supone frecuentemente la consideración de mero sentimentalismo, de paternalismo, que no toca sino la superficie del problema. B XVI trata de penetrar el verdadero sentido de la caridad cristiana de sentido mucho más amplio y profundo. "Se ha de buscar, encontrar y expresar la verdad en la «economía» de la caridad, pero, a su vez, se ha de entender, valorar y practicar la caridad a la luz de la verdad... Sin verdad, la caridad cae en mero sentimentalismo. El amor se convierte en un envoltorio vacío que se rellena arbitrariamente. Éste es el riesgo fatal del amor en una cultura sin verdad. Es presa fácil de las emociones y las opiniones contingentes de los sujetos, una palabra de la que se abusa y que se distorsiona, terminando por significar lo contrario... Un cristianismo de caridad sin verdad se puede confundir fácilmente con una reserva de buenos sentimientos, provechosos para la convivencia social, pero marginales". (nn. 2, 3, 4)

Caridad en la verdad en el cristianismo, según las líneas de la encíclica, es principio operativo que trata de profundizar no en sentimientos marginales de la sociedad, sino en criterios orientadores, dos de ellos de máxima repercusión: la justicia y el bien común

La justicia, ante todo, "dar a cada uno lo suyo", principio de resonancia bíblica continuada, pero que para el cristiano intenta añadir con la caridad un plus de fraternidad, "dar de lo mío al otro", ofrecer como entrega gratuita, y, más difícil, responder, si llega el caso, no con ira sino con perdón. Ante todo, la justicia. Ubi societas, ibi ius: toda sociedad elabora un sistema propio de justicia. La caridad va más allá de la justicia, porque amar es dar, ofrecer de lo «mío» al otro; pero nunca carece de justicia, la cual lleva a dar al otro lo que es «suyo», lo que le corresponde en virtud de su ser y de su obrar. No puedo «dar» al otro de lo mío sin haberle dado en primer lugar lo que en justicia le corresponde. Quien ama con caridad a los demás, es ante todo justo con ellos. No basta decir que la justicia no es extraña a la caridad, que no es una vía alternativa o paralela a la caridad: la justicia es «inseparable de la caridad» intrínseca a ella”. (n. 6)

Por otra parte, el bien común, como criterio orientador, "exigencia de la justicia y de la caridad", como indica la encíclica, establece el bien individual, desde luego, pero relacionado con el vivir social de las personas. Bien común, que en la sociedad actual globalizada no puede menos de pretender abarcar nada menos que a toda la comunidad de la familia humana. Amar a alguien es querer su bien y trabajar eficazmente por él. Junto al bien individual, hay un bien relacionado con el vivir social de las personas: el bien común. Es el bien de ese «todos nosotros», formado por individuos, familias y grupos intermedios que se unen en comunidad social" " En una sociedad en vías de globalización (señalaba Juan XXIII "Pacem in terris"), el bien común y el esfuerzo por él, han de abarcar necesariamente a toda la familia humana, es decir, a la comunidad de los pueblos y naciones. (n. 7) ${ }^{8}$

B XVI no ha podido prescindir de la encíclica "Populorum progressio" de Pablo VI, 1967, que trazó con penetrante mirada esta dimensión cristiana de la caridad: "A más de cuarenta años de su publicación, la relectura de la "Populorum progressio" insta a permanecer fieles a su mensaje de caridad y de verdad, considerándolo en el ámbito del

\footnotetext{
${ }^{8}$ Juan XXIII: "Pacem in terris", carta encíclica, AAS 55 (1963), (11 abril 1963), pp. 268-270.
} 
magisterio específico de Pablo VI y, más en general, dentro de la tradición de la doctrina social de la Iglesia" . Alude al fundamento de los apóstoles, Padres y doctores cristianos, y a los pontífices de los tiempos cercanos, que escribieron sobre esta doctrina, León XIII, Pío XI, Juan XXIII, Pablo VI, Juan Pablo II. (nn. 15, 16). ${ }^{9}$ Todo un compendio doctrinal y todo un patrimonio antiguo y nuevo, fuera del cual la "Populorum progressio" sería un documento sin raíces, cuyas cuestiones sobre el desarrollo se reducirían únicamente a datos sociológicos, referidos a lo que Pablo VI entendía por "desarrollo" : "ante todo el objetivo de que los pueblos salieran del hambre, la miseria, las enfermedades endémicas y el analfabetismo" (n. 21).

Pablo VI partía precisamente de esta visión para decirnos dos grandes verdades. La primera es que "toda la Iglesia, en todo su ser y obrar, cuando anuncia, celebra y actúa en la caridad, tiende a promover el desarrollo integral del hombre"... La segunda verdad es que "el auténtico desarrollo del hombre concierne de manera unitaria a la totalidad de la persona en todas sus dimensiones... Sin la perspectiva de una vida eterna, el progreso humano en este mundo se queda sin aliento. Encerrado dentro de la historia queda expuesto al riesgo de reducirse sólo al incremento del tener"... "Desafortunadamente, se ha depositado una confianza excesiva en dichas instituciones, sigue señalando B XVI, casi como si ellas pudieran conseguir el objetivo deseado de manera automática. En realidad, las instituciones por sí solas no bastan, porque el desarrollo humano integral es ante todo vocación y, por tanto, comporta que se asuman libre y solidariamente responsabilidades por parte de todos. Este desarrollo exige, además, una visión trascendente de la persona, necesita a Dios: sin Él, o se niega el desarrollo, o se le deja únicamente en manos del hombre, que cede a la presunción de la auto-salvación y termina por promover un desarrollo deshumanizado”. (n. 11)

Pablo VI indicó en el desarrollo, humana y cristianamente entendido, el corazón del mensaje social cristiano y propuso la caridad cristiana como principal fuerza al servicio del desarrollo.

Al contemplar el estado de subdesarrollo de tantos pueblos, considera la Iglesia como propia responsabilidad, en coincidencia con otros muchos analistas, que su causa no es sólo de orden material, y que por tanto las instituciones que tratan de superar, y que emplean con elogiable empeño medios materiales (estructurales, alimenticios, económicos...) no cubrirían una responsabilidad totalmente solidaria, si falta voluntad y pensamiento de desarrollo integral del hombre y si falta auténtica fraternidad.

\section{Desarrollo humano en la reflexión actual}

Después de muchos años de la "Populorum progressio", y desde luego también de otros muchos esfuerzos humanos de muchas instituciones, los problemas no han disminuido sino

\footnotetext{
9 León XIII: "Rerum novarum", carta encíclica (15 mayo 1891); Pío XI: "Quadragessimo anno", carta encíclica, AAS (1931) (15 mayo 1931), pp. 177-228; Juan XXIII: "Pacem in terris" carta encíclica, AAS 55(1963) (11 abril 1963); Pablo VI: "Populorum progressio", carta encíclica, 22: AAS 59 (1967) (26 marzo 1967), pp. 257-299; Pablo VI: “Octogesima adveniens”, carta apostólica, AAS 63 (1971) (14 mayo 1971); Juan Pablo II: "Laborem exercens", carta encíclica, AAS 73 (1981) (14 septiembre 1981); Juan Pablo II: "Sollicitudo rei socialis", carta encíclica, AAS 80 (1988) (30 diciembre 1987); Juan Pablo II: "Centesimus annus", carta encíclica, AAS 83 (1991) (1 mayo 1991).
} 
que se han aumentado y han surgido nuevas deficiencias. Por ello la "Caritas in veritate" insiste en que "se han de valorar después los diversos términos en que hoy, a diferencia de entonces ("Populorum progressio", 1967), se plantea el problema del desarrollo".

El desarrollo sigue siendo un factor positivo, sin duda, pero la sensación es que se producen en la actualidad desviaciones dramáticas.

"Es verdad que el desarrollo ha sido y sigue siendo un factor positivo que ha sacado de la miseria a miles de millones de personas y que, últimamente, ha dado a muchos países la posibilidad de participar efectivamente en la política internacional. Sin embargo, se ha de reconocer que el desarrollo económico mismo ha estado, y lo está aún, aquejado por desviaciones y problemas dramáticos, que la crisis actual ha puesto todavía más de manifiesto”. (n. 21)

B XVI, en nueva llamada de atención para los fieles de la Iglesia, continúa enumerando algunas desviaciones bien conocidas en la esfera internacional, como la propia actividad económica y financiera de los pueblos excesivamente especulativa, los flujos migratorios de carácter laboral tantas veces programados e insuficientemente gestionados, el grave problema del hambre en tantos pueblos, falta de agua y alimentos, incrementada no tanto por la escasez material como por insuficiencia de recursos sociales adecuados, la propia vida humana, derecho universal fundamental de todos los humanos sin discriminación, sometida a nuevos controles de mentalidad antinatalista, contracepción, aborto, eutanasia, como si constituyeran auténtico progreso cultural, añadidos a la ingente mortalidad infantil.

Con razón B XVI se une a la queja por muchos expresada: Los pueblos hambrientos interpelan hoy frecuentemente a los pueblos opulentos, entre otras razones porque las ayudas destinadas a los pueblos necesitados adolecen no pocas veces de sustraer para la organización burocrática cantidades importantes de la propia donación, que queda dramáticamente enflaquecida al llegar a su destino. (n. 17)

"La riqueza mundial crece en términos absolutos, pero aumentan también las desigualdades. En los países ricos, nuevas categorías sociales se empobrecen y nacen nuevas pobrezas. En las zonas más pobres, algunos grupos gozan de un tipo de superdesarrollo derrochador y consumista, que contrasta de modo inaceptable con situaciones persistentes de miseria deshumanizadora. Se sigue produciendo «el escándalo de las disparidades hirientes»". (n. 22)

El desarrollo, por tanto, sigue siendo un problema abierto, acentuado además con la crisis económica actual de los últimos años. La investigación científica no puede prescindir, señala la encíclica, de una valoración moral y mucho menos en la interdependencia planetaria de los pueblos, en la globalización, donde el progreso carecería de eficacia y engendraría nuevos daños y divisiones en la familia humana. B XVI estimula a los cristianos al esfuerzo hacia una caridad y verdad de sentido auténticamente humano y cristiano ya que el hombre en su integridad, toda la humanidad, es al mismo tiempo, debe ser, la causa, el medio y el fin sustancial del desarrollo.

Sobre esta caridad, esta fraternidad, se pregunta B XVI: "El subdesarrollo tiene una causa más importante aún que la falta de pensamiento: es «la falta de fraternidad entre los hombres y entre los pueblos» ¿podrán lograrla alguna vez los hombres por sí solos? La sociedad cada vez más globalizada nos hace más cercanos, pero no más hermanos. La razón, por sí sola, es capaz de aceptar la igualdad entre los hombres y de establecer una 
convivencia cívica entre ellos, pero no consigue fundar la hermandad. Ésta nace de una vocación transcendente de Dios Padre, el primero que nos ha amado, y que nos ha enseñado mediante el Hijo lo que es la caridad fraterna" (n.19).

La Iglesia se siente responsable para alcanzar no sólo una convivencia cívica, sino una convivencia fraterna. Las instituciones sólas no bastan si carecen de responsabilidad solidaria.

\section{El hombre autosuficiente}

La reflexión de la encíclica recae, en determinado momento (cap. 3), sobre el hombre cuando es considerado como único factor de sí mismo, de su vida y de la sociedad. La consideración del hombre como autosificiente sería errónea teniendo en cuenta que su bienestar material depende de otros factores sociales con los que está relacionado. Hay dependencias inevitables, ya que el hombre no se hace asímismo, recibe su vida y sus facultades de forma gratuita. Otro tanto cabe decir de la lógica mercantil, señala B XVI, que no sería de recibo si se gestiona sólo con referencias egoistas, debiendo tener encuenta el bien común.

"Creerse autosuficiente y capaz de eliminar por sí mismo el mal de la historia ha inducido al hombre a confundir la felicidad y la salvación con formas inmanentes de bienestar material y de actuación social. Además, la exigencia de la economía de ser autónoma, de no estar sujeta a «injerencias» de carácter moral, ha llevado al hombre a abusar de los instrumentos económicos incluso de manera destructiva. Con el pasar del tiempo, estas posturas han desembocado en sistemas económicos, sociales y políticos que han tiranizado la libertad de la persona y de los organismos sociales y que, precisamente por eso, no han sido capaces de asegurar la justicia que prometían"... Sin formas internas de solidaridad y de confianza recíproca, el mercado no puede cumplir plenamente su propia función económica. Hoy, precisamente esta confianza ha fallado, y esta pérdida de confianza es algo realmente grave" (nn.34 y 35$)$

La doctrina social de la Iglesia, aun comprendiendo la grave dificultad de llevar a la práctica lo que sugieren las ideas, siempre ha considerado la actividad humana interdependiente con otras relaciones humanas de solidaridad, reciprocidad, con apertura progresiva en el contexto mundial a márgenes no exclusivamente utilitarios de carácter personal, sino abiertos a la solidaridad y gratuidad. "La doctrina social de la Iglesia sostiene que se pueden vivir relaciones auténticamente humanas, de amistad y de sociabilidad, de solidaridad y de reciprocidad, también dentro de la actividad económica y no solamente fuera o «después» de ella. El sector económico no es ni éticamente neutro ni inhumano o antisocial por naturaleza. Es una actividad del hombre y, precisamente porque es humana, debe ser articulada e institucionalizada éticamente” (n.36)

Observa, desde luego, B XVI al acercarse al tema de la empresa, como otros muchos pensadores, el buen camino recorrido por la misma, bien sea por razones de signo humanista o de signo sindical, no exclusivamente utilitarista, abriéndose a responsabilidades sociales no sólo de los directivos, sino también de los trabajadores, clientes, proveedores, de suerte que su programa de actividades ha ido acogiendo un significado polivalente del mejor sentido, aunque distante del bien común solidario. Movimiento también aplicable por sus mejoras y defectos a los responsables de los pueblos que con muy variada política gestionan a nivel más amplio el bienestar de los ciudadanos. Pero esta observación optimista ha de ser coordinada con resposabilidades más amplias: "La obtención de recursos, la financiación, la producción, 
el consumo y todas las fases del proceso económico tienen ineludiblemente implicaciones morales. Así, toda decisión económica tiene consecuencias de carácter moral. Lo confirman las ciencias sociales y las tendencias de la economía contemporánea...También la autoridad política tiene un significado polivalente, que no se puede olvidar mientras se camina hacia la consecución de un nuevo orden económico-productivo, socialmente responsable y a medida del hombre." (nn. 40, 41)

Finalmente, a nivel mundial, en el proceso socioeconómico hacia la globalización resulta también imprescindible contar con la finalidad de relación interhumana: el desarrollo no debe prescindir de ser útil a las personas y a los pueblos. Por eso la encíclica subraya, dirigiéndose al mundo cristiano, la obligación de tratar de caminar por los aspectos positivos, aunque sean difíciles, siendo protagonistas, no víctimas del progreso, procediendo razonablemente guiados por el aludido sentido de la caridad y de la verdad según la ruta del Evangelio. La riqueza a escala planetaria bien gestionada no deberá engendrar ni pobreza ni desigualdad, sino que ha de tratar de superar las dificultades y peligros con espíritu verdaderamente humano y ético del mejor sentido hacia una globalización auténticamente solidaria.

"A pesar de algunos aspectos estructurales innegables, pero que no se deben absolutizar, la globalización no es, a priori, ni buena ni mala. Será lo que la gente haga de ella». Debemos ser sus protagonistas, no las víctimas, procediendo razonablemente, guiados por la caridad y la verdad. Oponerse ciegamente a la globalización sería una actitud errónea, preconcebida, que acabaría por ignorar un proceso que tiene también aspectos positivos, con el riesgo de perder una gran ocasión para aprovechar las múltiples oportunidades de desarrollo que ofrece. El proceso de globalización, adecuadamente entendido y gestionado, ofrece la posibilidad de una gran redistribución de la riqueza a escala planetaria como nunca se ha visto antes; pero, si se gestiona mal, puede incrementar la pobreza y la desigualdad, contagiando además con una crisis a todo el mundo"(n. 42).

\section{Derechos y deberes del desarrollo}

A la hora de examinar los derechos y deberes en el proceso del desarrollo, la encíclica subraya una verdad bien conocida: que todo derecho engendra sus correspondientes deberes. " $L a$ solidaridad universal, que es un hecho y un beneficio para todos, es también un deber». En la actualidad, muchos pretenden pensar que no deben nada a nadie, si no es a sí mismos. Piensan que sólo son titulares de derechos y con frecuencia les cuesta madurar en su responsabilidad respecto al desarrollo integral propio y ajeno. Por ello, es importante urgir una nueva reflexión sobre los deberes que los derechos presuponen, y sin los cuales éstos se convierten en algo arbitrario... La exacerbación de los derechos conduce al olvido de los deberes. Los deberes delimitan los derechos porque remiten a un marco antropológico y ético en cuya verdad se insertan también los derechos y así dejan de ser arbitrarios” (n. 43)

A veces, sin embargo, se reclaman presuntos derechos arbitrarios y superfluos, al mismo tiempo que se inculcan derechos fundamentales de personas y de pueblos. También sucede que determinadas ayudas al desarrollo son empleadas para "mantener costosos organismos burocráticos", llegando muy mermadas a sus destinatarios principales: "Hoy se da una profunda contradicción. Mientras, por un lado, se reivindican presuntos derechos, de carácter arbitrario y superfluo, con la pretensión de que las estructuras públicas los reconozcan y promuevan, por otro, hay derechos elementales y fundamentales que se ignoran 
$y$ violan en gran parte de la humanidad. Se aprecia con frecuencia una relación entre la reivindicación del derecho a lo superfluo, e incluso a la transgresión y al vicio, en las sociedades opulentas, y la carencia de comida, agua potable, instrucción básica o cuidados sanitarios elementales en ciertas regiones del mundo subdesarrollado y también en la periferia de las grandes ciudades.”...(n. 43).

El acento se pone principalmente en un par de cuestiones fundamentales para la población, que ofrecen derechos y deberes a escala universal, que son objeto de análisis y consecuencias de gran alcance por los pensadores y por los responsables de la dirección de los países, dos temas con un sinfín de consecuencias sociales, la demografía y la naturaleza, sobre los que se pronuncia B XVI en la encíclica.

Demografía. Bajo esta expresión son bien conocidas numerosas realidades, que engendran constante proeocupación en los gestores de la dirección de los pueblos, de las agregaciones de países unidos y prácticamente en los responsables de los cinco continentes, ya que su alcance se proyecta hacia el presente y hacia el futuro de la humanidad. " $L a$ concepción de los derechos y de los deberes respecto al desarrollo, debe tener también en cuenta los problemas relacionados con el crecimiento demográfico. Es un aspecto muy importante del verdadero desarrollo, porque afecta a los valores irrenunciables de la vida y de la familia" (n. 44).

Derecho a la vida. Ante todo el derecho a la vida de las personas, de cada persona, tutelado como derecho fundamental en las leyes constitucionales de los países, pero que en la práctica se ve sometido a numerosas limitaciones de grave repercusión. Las estadísticas, en efecto, señalan al mismo tiempo en la diversidad de los pueblos el aumento o disminución de la natalidad según las diversas políticas empleadas en su protección. B XVI consigna como preocupación importante (cap. $2^{\circ}, \mathrm{nn} 27,28 \ldots$ ) que los propios gobiernos de la causa pública son los primeros en acusar los riesgos de una demografía que fluctúa entre el favor y las limitaciones, cuando se abordan las leyes sobre temas como el aborto, la planificación forzada de la natalidad, el tratamiento genético de embriones, la sexualidad reducida a simple fuente de placer, y por otra parte cuando se trata de establecer legislación sobre el final de la vida de las personas con diversas formas de eutanasia, que oscilan con finalidades de legitimidad a veces discutible, en difícil equilibrio, entre el derecho a la vida singular de las personas y el bienestar de los pueblos a corto o a largo espacio de tiempo.

"La disminución de los nacimientos, a veces por debajo del llamado «índice de reemplazo generacional», pone en crisis incluso a los sistemas de asistencia social, aumenta los costes, merma la reserva del ahorro y, consiguientemente, los recursos financieros necesarios para las inversiones, reduce la disponibilidad de trabajadores cualificados y disminuye la reserva de «cerebros» a los que recurrir para las necesidades de la nación".(n. 44)

Lógicamente B XVI al dirigirse a los fieles cristianos expone y urge ante los mismos las conocidas tesis cristianas relativas a estos temas, consciente de la dificultad que algunas presentan ante corrientes del pensamiento moderno, pero tratando de llevar la responsabilidad religiosa por la ruta de la doctrina evangélica en orden al bien común de los hombres.

Matrimonio y familia. A este cúmulo de derechos y obligaciones con respecto al derecho a la vida, son de añadir, desde luego, como lo hace B XVI en la encíclica y en otras 
muchas ocasiones, y como advertía con claridad el Vaticano II $^{10}$, las políticas referidas a dos instituciones de la mayor trascendencia en la historia de la humanidad y en la geografía de los continentes, el matrimonio y la familia, que constituyen la raiz fundamental de la sociedad y de la humanidad, y que no siempre obtienen el tratamiento social, jurídico y ético que merecen. “... Por eso, se convierte en una necesidad social, e incluso económica, seguir proponiendo a las nuevas generaciones la hermosura de la familia y del matrimonio, su sintonía con las exigencias más profundas del corazón y de la dignidad de la persona. En esta perspectiva, los estados están llamados a establecer políticas que promuevan la centralidad y la integridad de la familia, fundada en el matrimonio entre un hombre y una mujer, célula primordial y vital de la sociedad”. (n. 44)

La naturaleza. La mirada de la encíclica se proyecta, como no podía ser de otra manera, sobre la responsabilidad del hombre sobre los recursos de la naturaleza, sobre toda la naturaleza creada, una dimensión de consencuencias verdaderamene importantes y de alcanze casi incomprensible. Constituye, señala también B XVI siguiendo la tesis cristiana, una expresión bien clara, favorable y verdadera para el hombre, con responsabilidad insoslayable, ya que nos ha sido dada por el Creador para uso inteligente del hombre y no meramente instrumental ni arbitrario. Sobre la naturaleza reside en los pueblos y en sus gobiernos, y lo mismo se recalca en la cíclica para la multitud de fieles de la Iglesia, la difícil responsabilidad de un tratamiento razonable, que sirva para las generaciones presentes y futuras con la mejor andadura posible, y por tanto lejana de lo que puede considerarse en no pocas circunstancias como destrucción y planteamiento caótico.

Inquietud ecológica. Bajo la denominación de inquietud ecológica, señala la encíclica, donde son destacables los múltiples pasos positivos en los siglos cercanos y en los últimos decenios, gracias a investigadores, científicos, políticos y tantos otros profesionales responsables, es de interés subrayar, al menos, una doble perspectiva complementaria e imprescindible, la potenciación tanto de una ecología ambiental como una ecología humana, ya que el hombre influye en el ámbiente natural, y el ambiente natural influye en el hombre.

"Para salvaguardar la naturaleza no basta intervenir con incentivos o desincentivos económicos, y ni siquiera basta con una instrucción adecuada. Éstos son instrumentos importantes, pero el problema decisivo es la capacidad moral global de la sociedad... Los deberes que tenemos con el ambiente están relacionados con los que tenemos para con la persona considerada en sí misma y en su relación con los otros. No se pueden exigir unos y conculcar otros. Es una grave antinomia de la mentalidad y de la praxis actual, que envilece a la persona, trastorna el ambiente y daña a la sociedad" (n. 51)

La Iglesia se siente responsable de manera especial, junto a otros muchos agentes del bien común, hacia el cuidado de la naturaleza tanto para las presentes generaciones como para las futuras, ya que en su credo figura de manera destacada la donación gratuita del mundo y de los recursos de la naturaleza por parte del Creador para el mejor uso y utilidad de la humanidad. Los desastres naturales, tantas veces catastróficos y por otra parte los graves desperfectos producidos por el hombre en la naturaleza por descuido o de forma intencionada son preocupación de primer orden que exige atención continuada dentro de esa doble potenciación aludida de ecología ambiental y ecología humana.

\footnotetext{
${ }^{10}$ Concilio Ecuménico Vaticano II: Apostolicam actuoritatem, decreto sobre el apostolado de los laicos, n.11 sobre la familia, AAS 58 (1966), pp. 847-848.
} 
La técnica. La técnica, actividad prevalente en el campo humano y en la que el hombre se considera dueño y dominador de tantos secretos de la naturaleza orgánica e inorgánica, señala B XVI, es un "hecho profundamente humano, vinculado a la autonomía y libertad del hombre. En la técnica se manifiesta y confirma el dominio del espíritu sobre la materia"... "La clave del desarrollo está en una inteligencia capaz de entender la técnica y de captar el significado plenamente humano del quehacer del hombre, según el horizonte de sentido de la persona considerada en la globalidad de su ser. Incluso cuando el hombre opera a través de un satélite o de un impulso electrónico a distancia, su actuar permanece siempre humano, expresión de una libertad responsable. La técnica atrae fuertemente al hombre, porque lo rescata de las limitaciones físicas y le amplía el horizonte. Pero la libertad humana es ella misma sólo cuando responde a esta atracción de la técnica con decisiones que son fruto de la responsabilidad moral. De ahí la necesidad apremiante de una formación para un uso ético y responsable de la técnica". (n. 70)

La ética. Una ulterior advertencia de interés es proyectada en la encíclica al término del capítulo de derechos y deberes, sobre la denominada "responsabilidad ética", que se incorpora a veces con facilidad en tareas de bien común con pretensión de aparente honradez , pero que pueden rozar la frontera de intereses menos éticos o antiéticos. Las palabras de B XVI aclaran con lucidez esta advertencia:

"Hoy se habla mucho de ética en el campo económico, bancario y empresarial. Surgen centros de estudio y programas formativos de business ethics; se difunde en el mundo desarrollado el sistema de certificaciones éticas, siguiendo la línea del movimiento de ideas nacido en torno a la responsabilidad social de la empresa. Los bancos proponen cuentas y fondos de inversión llamados «éticos». Se desarrolla una «finanza ética», sobre todo mediante el microcrédito y, más en general, la microfinanciación. Dichos procesos son apreciados y merecen un amplio apoyo. Sus efectos positivos llegan incluso a las áreas menos desarrolladas de la tierra. Conviene, sin embargo, elaborar un criterio de discernimiento válido, pues se nota un cierto abuso del adjetivo «ético» que, usado de manera genérica, puede abarcar también contenidos completamente distintos, hasta el punto de hacer pasar por éticas decisiones y opciones contrarias a la justicia y al verdadero bien del hombre." (n. 45)

\section{Desarrollo de la familia humana global}

La encíclica se acerca antes del final (cap. V) al tema de la familia humana en su más amplio sentido, centro y finalidad fundamental del desarrollo de los pueblos.

Parte de la referencia a la soledad obligada de las personas y de los pueblos como síntoma de una gran pobreza tantas veces material y espiritual, y de un punto de necesaria atención para llegar al verdadero desarrollo. El desarrollo de los pueblos supone reconocerse como parte de la familia humana que alcanza, debe alcanzar, las relaciones interpersonales con los otros, las relaciones interpueblos, sin olvidar la relación trascendente con Dios, autor de las personas, de la humanidad, de la creación. "Hoy la humanidad aparece mucho más interactiva que antes: esa mayor vecindad debe transformarse en verdadera comunión. El desarrollo de los pueblos depende sobre todo de que se reconozcan como parte de una sola familia, que colabora con verdadera comunión y está integrada por seres que no viven simplemente uno junto al otro ...La criatura humana, en cuanto de naturaleza espiritual, se realiza en las relaciones interpersonales. Cuanto más las vive de manera auténtica, tanto más 
madura también es la propia identidad personal. El hombre se valoriza no aislándose sino poniéndose en relación con los otros y con Dios. Por tanto, la importancia de dichas relaciones es fundamental. Esto vale también para los pueblos" (n 53)

El desarrollo de la familia humana, recuerda B XVI, comprende también, no puede prescindir de la relación a las culturas diversas según los tiempos y los grupos humanos, así como también la relación a las religiones, ya que unas y otras, culturas y religiones colaboran, pueden colaborar de manera nada despreciable a la fraternidad y a la paz de la humanidad, siempre naturalmente que su acción sea favorable al bien común. "La revelación cristiana sobre la unidad del género humano presupone una interpretación metafísica del humanum, en la que la relacionalidad es elemento esencial. También otras culturas y otras religiones enseñan la fraternidad y la paz y, por tanto, son de gran importancia para el desarrollo humano integral" (n. 55)

La reflexión sobre el tema religioso lleva a B XVI a la pregunta de hondo calado social, "si Dios tiene lugar en la esfera pública", en una sociedad que se muestra de muy diversas formas, deseosa de eliminar toda manifestación religiosa considerando el factor religioso como elemento puramente interno del ámbito de la conciencia personal y contrario al progreso humano. Pero cabría preguntarse si una sociedad es auténticamente democrática cuando proclama el laicismo excluyente como dogma y niega el estado de ciudadanía al factor religioso, al mismo tiempo que defiende la carta de los derechos humanos fundamentales, entre ellos la libertad de expresión, la igualdad ante la ley, la libertad religiosa. El derecho de libertad religiosa, lo mismo que los demás derechos fundamentales de la persona, no son mera elaboración de la conciencia personal, limitada al ámbito de la misma, sino que incluye en el ordenamiento jurídico la protección de su manifestación exterior y los demás derechos, incluido el de asociación, y la realización de su actividad promotora del progreso humano en el orden cultural y humanitario, además del estrictamente religioso, lógicamente siempre que no sea contraria al bien común.

"La religión cristiana y las otras religiones pueden contribuir al desarrollo solamente si Dios tiene un lugar en la esfera pública, con específica referencia a la dimensión cultural, social, económica y, en particular, política. La doctrina social de la Iglesia ha nacido para reivindicar esa «carta de ciudadanía» de la religión cristiana. La negación del derecho a profesar públicamente la propia religión y a trabajar para que las verdades de la fe inspiren también la vida pública, tiene consecuencias negativas sobre el verdadero desarrollo... Se corre el riesgo de que no se respeten los derechos humanos, bien porque se les priva de su fundamento trascendente, bien porque no se reconoce la libertad personal' (n. 56)

A este propósito cabría señalar aquí el pensamiento de Joseph H. Weiler profesor de Derecho, Universidad de Nueva York, sobre textos constitucionales, que, "al pronunciar el Estado como "laico", manifiestan ciertamente con ello su adhesión explícita al laicismo de una parte de la población, pero dejan en silencio la vivencia religiosa de otra buena parte de población, quizás mayoritaria, como si el laicismo gozase de carta de ciudadanía y la religiosidad hubiera de ser escondida en la conciencia individual..." En el camino de una verdadera democracia se pregunta "¿Por qué el excluir una referencia a Dios va a ser más neutral que el incluir a Dios? En una condición binaria, ninguna opción es neutra...”. 11

11 Weiler, Joseph H.H.: (profesor de Derecho.Universidad de Nueva York y cátedra Jean Monet. Unión Europea), Invocatio Dei y la Constitución Española (www.conoze.com n. 438). 
La encíclica además desea promocionar la colaboración fraterna de creyentes y no creyentes, en tantos posibles campos favorables al desarrollo humano, además de la convivencia pacífica de unos con otros, propiciada desde muchas instancias sociales y políticas, y también desde la Iglesia de manera esplícita por la constitución "Gaudium et spes" del Vaticano II y tantos otros documentos, ya que es el hombre el centro y culmen del desarrollo. $^{12}$

Sin necesidad de acudir a legislaciones positivas de ordenamientos jurídicos cabe aludir a la fuerte inclinación humana hacia el bien y la verdad, hacia la honradez de las personas, una especie de exigencia connatural, considerada por muchos como ley natural, que se manifiesta en la conciencia personal y en la expresión de la naturaleza, y que resulta ser la fuente radical de la elaboración de los derechos humanos fundamentales de los ordenamientos jurídicos. "Dicha ley moral universal es fundamento sólido de todo diálogo cultural, religioso y político, ayudando al pluralismo multiforme de las diversas culturas a que no se alejen de la búsqueda común de la verdad, del bien y de Dios. Por tanto, la adhesión a esa ley escrita en los corazones es la base de toda colaboración social constructiva.” (n.59)

La difícil andadura de este desarrollo interhumano, interpersonal y de los pueblos, inclina a pensar en la necesidad, expresada en numerosas instancias de todo color social y político, de una Autoridad Política Mundial que conduzca eficazmente al auténtico desarrollo humano, como expresa B XVI y como señaló en su momento Juan XXIII. ${ }^{13}$

\section{Conclusión}

La clave del desarrollo debe tener, sin duda, un significado plenamente humano por encima de esfuerzos meramente técnicos o económicos. La conclusión de B XVI, al contemplar la dimensión trascendente del hombre según la fe cristiana sobre el desarrollo, evoca un proceso a la vez material y espiritual congruente con el dominio del espíritu sobre la materia.

“El tema del desarrollo de los pueblos está íntimamente unido al del desarrollo de cada hombre. La persona humana tiende por naturaleza a su propio desarrollo. Éste no está garantizado por una serie de mecanismos naturales, sino que cada uno de nosotros es consciente de su capacidad de decidir libre y responsablemente. Tampoco se trata de un desarrollo a merced de nuestro capricho, ya que todos sabemos que somos un don y no el resultado de una autogeneración.... No sólo las demás personas se nos presentan como no disponibles, sino también nosotros para nosotros mismos...” (69)

\footnotetext{
${ }^{12}$ Concilio Ecuménico Vaticano II: “Gaudium et spes”, Constitución Pastoral n. 12: "Creyentes y no creyentes están generalmente de acuerdo en este punto, todos los bienes de la tierra deben ordenarse en función del hombre como su centro y cima de todos ellos». B XVI: "Para los creyentes, el mundo no es fruto de la casualidad ni de la necesidad, sino de un proyecto de Dios. De ahí nace el deber de los creyentes de aunar sus esfuerzos con todos los hombres y mujeres de buena voluntad de otras religiones, o no creyentes, para que nuestro mundo responda efectivamente al proyecto divino: vivir como una familia, bajo la mirada del Creador", n. 57.

13 Juan XXIII: "Pacem in terris", carta encíclica, AAS 55 (1963) 293: (11 abril 1963), p. 137: "Y como hoy el bien común de todos los pueblos plantea problemas que afectan a todas las naciones, y como semejantes problemas solamente puede afrontarlos una autoridad pública cuyo poder, estructura y medios sean suficientemente amplios y cuyo radio de acción tenga un alcance mundial, resulta, en consecuencia, que, por imposición del mismo orden moral, es preciso constituir una autoridad pública general”; p. 138: "Esta autoridad general, cuyo poder debe alcanzar vigencia en el mundo entero y poseer medios idóneos para conducir al bien común universal, ha de establecerse con el consentimiento de todas las naciones y no imponerse por la fuerza".
} 
En la línea de la fe cristiana B XVI concluye su encíclica a la hora del desarrollo humano y cristiano con expresiónes sugeridas desde la misma fe: "La disponibilidad para con Dios provoca la disponibilidad para con los hermanos y una vida entendida como una tarea solidaria y gozosa. Al contrario, la cerrazón ideológica a Dios y el indiferentismo ateo, que olvida al Creador y corre el peligro de olvidar también los valores humanos, se presentan hoy como uno de los mayores obstáculos para el desarrollo...." Añade las palabras de San Pablo a los Romanos: "Que vuestra caridad no sea una farsa: aborreced lo malo y apegaos a lo bueno. Como buenos hermanos, sed cariñosos unos con otros, estimando a los demás más que a uno mismo» (12,9-10). (nn. 78 y 79) 